\title{
Morphological abnormalities in the testes and epididymides of roe deer that affect spermatogenesis
}

\author{
Ilya Sosnovsky ${ }^{1, *}$, Natalia Kukharenko ${ }^{1}$, Alexander Senchik ${ }^{1}$, and Vyacheslav Gogulov ${ }^{1}$ \\ ${ }^{1}$ Far Eastern State Agrarian University, Blagoveshchensk, Russia
}

\begin{abstract}
In the wild fauna of the Amur region there has been a decrease in the population of Siberian roe deer in recent years. Abnormalities associated with loss of reproductive quality affect the number of animals. When analyzing pathological abnormalities in the reproductive organs, it is important to take into account not only the morphology in the structure of the genitals, but also the defective development of spermatozoa. The aim of this research is to study the influence of morphological deviations in the testes and epididymides in male Siberian roe deer on the development of spermatozoa.The object of the study was 24 males of Siberian roe deer aged from 1 to 6 years old; they were divided into 2 groups of 12 individuals each, from which the testes with epididymides were selected, and visual morphometric and histological studies were performed using generally accepted methods. Morphological abnormalities in roe deer were observed at the age of up to 1 year old. The greatest number of pathologies was found in male roe deer aged from 2 to 3 years old and older than 6 years old. Histological analysis of the testes and epididymides showed violations in the composition of the structural elements of this organ; they contribute to the further development of deviations. The main reason for the violation of spermatogenesis in roe deer is oligospermia, deformation of the convoluted seminal tubules, which leads to a violation of the development of gonadocytes.
\end{abstract}

\section{Introduction}

In modern veterinary medicine, one of the most important tasks is to solve problems associated with impaired reproductive qualities not only in agricultural livestock, but also among mammals of the wild fauna, especially those that are a feed link in the chain of carnivores. The territory of the Amur region is an area for Siberian roe deer (Capreolus Pygargus Pall). In 2016, when recording this species, 71196 individuals were found. However, since 2017 the total number of roe deer has decreased in the Amur region. In 2019 this figure was 53793 individuals. Despite the fact that anthropogenic factors [1,2], climatic factors [3-5], and the influence of predators [6] contribute to changes in the number of animals living in the wild fauna, abnormalities associated with the loss of reproductive qualities play a special role. Deviations in the organs of the genitals in males

\footnotetext{
*Corresponding author: sakhboy95@gmail.com
} 
can lead to a violation of full-fledged fertilization of the female. When analyzing pathologies in the reproductive organs, a wide range of questions is raised, related not only to morphological deviations in the structure of the genitals, but also to the defective development of spermatozoa. Since the extraction of ejaculate is very difficult in animals living in the wild fauna, histological studies of the testes and their epididymides during veneral excitement can help to detect the main shifts in the process of spermatogenesis.

The aim of the research is to study the influence of morphological deviations in the testes and their epididymides in male Siberian roe deer on the development of spermatozoa.

Tasks:

1. To determine the degree of severity of pathological changes, as well as the features of their manifestations in male roe deer of different age groups at the histomorphological level.

2. To describe the main histomorphological causes of spermatogenesis disorders in male Siberian roe deer.

\section{Materials and Methods}

The material was selected from 24 male Siberian roe deer aged from 1 to 6 years old, including:

- 12 at rest;

-12 during the rutting period.

The selection dates in the rut period (July - August) were chosen based on the authors' research [7-9]. The selected material including testes and their epididymides $(n=24)$ was placed in a $10 \%$ aqueous solution of neutral formalin for 14 days. For a more detailed analysis, the material studied was divided into 4 groups:

1. Fingerlings (roe deer at the age of 1 year old);

2. Males from 2 to 3 years old;

3. Males from 4 to 5 years old;

4. Males older than 5 years.

For each age group of animals, a monitoring map of morphological abnormalities in the testes and their epididymides was compiled and it took into account 16 indicators and 88 signs. When preparing histological sections, the material was dehydrated in alcohols of increasing strength and poured into paraffin. The sections were prepared on a sledge microtome. The staining was made with hematoxylin and eosin. To conduct a histomorphometric analysis, there was used a Micromed model microscope (maximum magnification x720), and an eyepiece micrometer MOV-1-16x. The obtained data were processed biometrically according to the generally accepted method.

\section{Results}

As a result of the analysis of all the studied groups of male roe deer, summary tables were compiled (Nos. 1 and 2), which show the number of morphological deviations in the testes and their epididymides.

During the analysis, it was found out that all individuals who were in the period of veneral excitement (rutting) had various types of pathology; in addition, 1/3 of the males had abnormalities in the reproductive organs in a calm veneral state. The age ratio of pathological cases is shown in figure 1.

Based on the data obtained, the highest frequency of changes was observed in individuals aged 2 to 3 years old $(34.7 \%)$ and older than 5 years $(33.3 \%)$. However, it should be noticed that pathological abnormalities were also found in individuals who have not reached pubescence: fingerlings. 
Table 1. Number of morphological deviations in male Siberian roe deer aged from 1 to 6 years old.

\begin{tabular}{|c|c|c|c|c|c|c|}
\hline \multirow{2}{*}{$\begin{array}{c}\text { The degree of } \\
\text { veneral } \\
\text { excitement }\end{array}$} & \multicolumn{2}{|c|}{$\begin{array}{c}\text { The number of } \\
\text { individuals }\end{array}$} & \multicolumn{2}{|c|}{$\begin{array}{c}\text { The individuals } \\
\text { without pathology }\end{array}$} & \multicolumn{2}{|c|}{$\begin{array}{c}\text { The individuals with } \\
\text { pathology }\end{array}$} \\
\cline { 2 - 7 } & Number & $\%$ & Number & $\%$ & Number & $\%$ \\
\hline Calm period & 12 & 100.0 & 8 & 66.7 & 4 & 33.3 \\
\hline Rutting & 12 & 100.0 & 0 & 0 & 12 & 100.0 \\
\hline Total & 24 & 100.0 & 8 & 33.3 & 16 & 66.7 \\
\hline
\end{tabular}

\section{3}

\section{3}

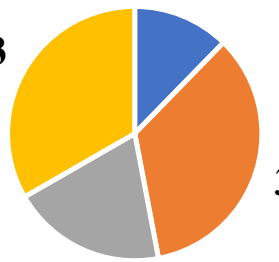

34.7

19.7

\section{- younger than 1 year old $\square$ from 2 to 3 years old \\ - from 4 to 5 years old $\quad$ older than 5 years old}

Fig. 1. The ratio of pathological deviations in males of the Siberian roe deer depending on age, $n=24$ $(100 \%$.).

Table 2. Nomenclature of deviations in males of Siberian roe deer aged from 1 to 7 years old; $n=24$.

\begin{tabular}{|c|c|c|c|c|}
\hline Indicator & Signs & $\begin{array}{l}\text { Calm } \\
\text { period }\end{array}$ & $\begin{array}{c}\text { Rutt } \\
\text { ing }\end{array}$ & $\begin{array}{c}\text { Total } \\
\text { number of } \\
\text { cases }\end{array}$ \\
\hline 1 & 2 & 3 & 4 & 5 \\
\hline \multirow{7}{*}{ Testes } & $\begin{array}{l}\text { Pathological forms of convoluted seminal } \\
\text { tubules }\end{array}$ & 4 & 12 & 16 \\
\hline & Abruption of the testis tubule coat & - & 7 & 7 \\
\hline & Rupture of the testis tubule & 4 & 5 & 9 \\
\hline & Disorders in spermatogenesis & - & 12 & 12 \\
\hline & $\begin{array}{l}\text { Violation in the development of } \\
\text { gonadocytes }\end{array}$ & 4 & 12 & 16 \\
\hline & $\begin{array}{l}\text { Structural abnormalities in the } \\
\text { interstitium }\end{array}$ & 4 & 8 & 12 \\
\hline & Oligospermia & - & 4 & 4 \\
\hline \multirow{7}{*}{ Epididymis } & Structural disorders in the mesenchyma & 4 & 5 & 9 \\
\hline & $\begin{array}{l}\text { Abruption of the coat of the duct } \\
\text { of epididymis }\end{array}$ & - & 4 & 4 \\
\hline & $\begin{array}{l}\text { Rupture of the duct of } \\
\text { epididymis }\end{array}$ & - & 2 & 2 \\
\hline & Presence of inclusions in the sperm fluid & - & 8 & 8 \\
\hline & Underdevelopment of spermatozoa & - & 8 & 8 \\
\hline & Cyst of the epididymis & - & 3 & 3 \\
\hline & Abnormal location of the epididymis & 1 & - & 1 \\
\hline
\end{tabular}


In the study of microscopic abnormalities, it was found out that in all cases there were polypathological changes, of which the vast majority were: deformation of the convoluted seminiferous tubules and a violation in the development of gonadocytes.

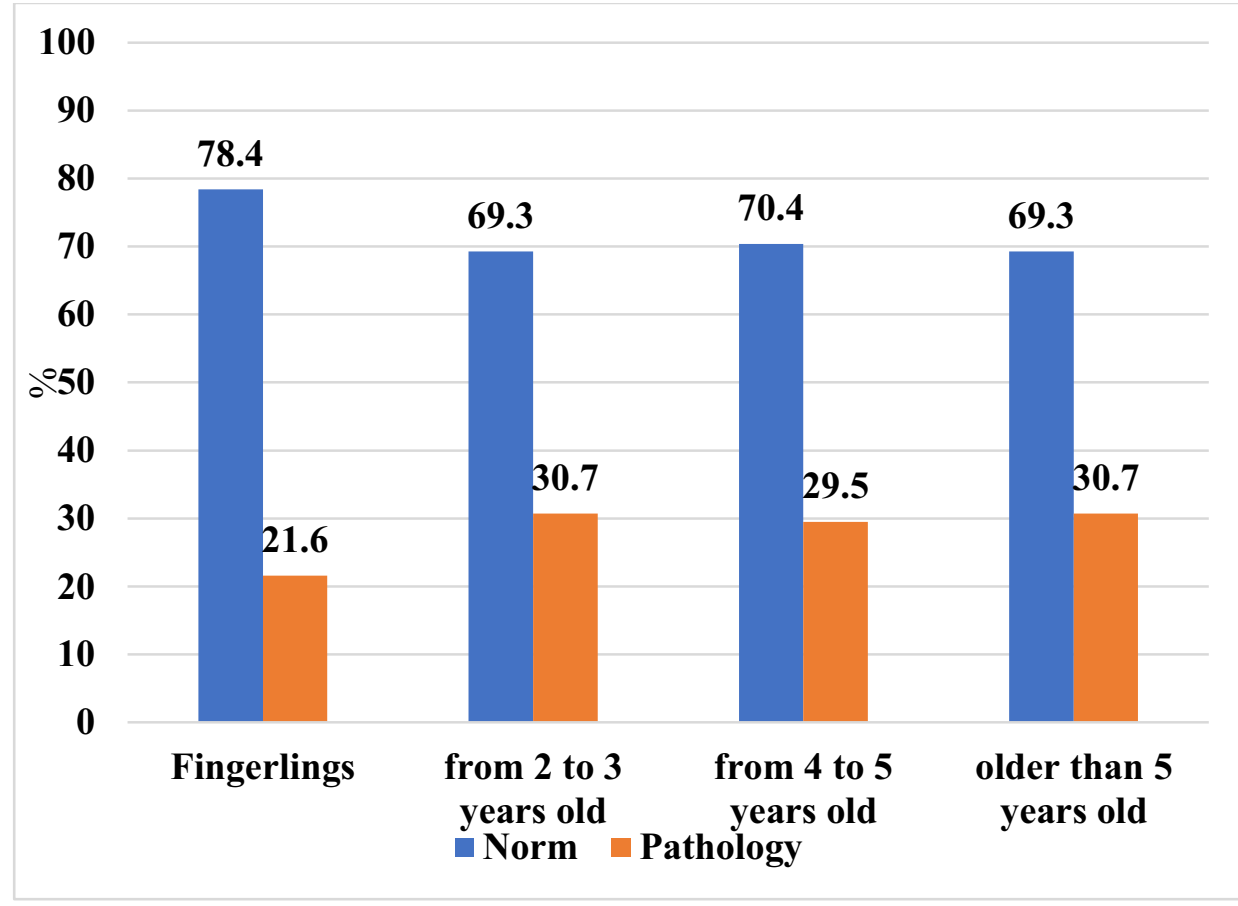

Fig. 2. Age-related pathological changes in male roe deer during rut, $\mathrm{n}=12(100 \%)$.

Based on the presented data, morphological deviations are observed in individuals who have not reached pubescence (fingerlings), and that is $21.6 \%$. Starting from males of 2 years old and ending with individuals older than 5 years old, the number of changes in the testes and their epididymides increases, and the rate of deviations varies within $29.5-$ $30.7 \%$. The share of pathological convoluted tubules in one testis was $63.4 \%$. In addition to the round-oval shapes, there were filamentous, pear-shaped, bean-shaped and double tubules (Fig. 3)

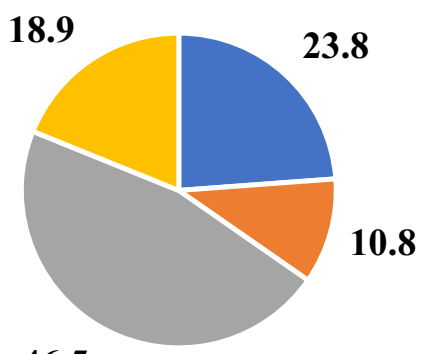

46.5

- bean-shaped $"$ pear-shaped $\approx$ filamentous $\approx$ double

Fig. 3. The ratio of shapes in the convoluted seminiferous tubules. 
The number of filamentous convoluted seminiferous tubules was $46.5 \%$, which was the highest value among all pathological forms. Pear-shaped tubules had the smallest number: $10.8 \%$. Due to changes in the shape of the convoluted seminiferous tubules, deviations in the layering of gonadocytes were observed, which presumably led to violations in the synthesis of these cells. For a more detailed analysis, gonadocytes in normal and pathological forms of convoluted seminiferous tubules were counted (Fig 4).

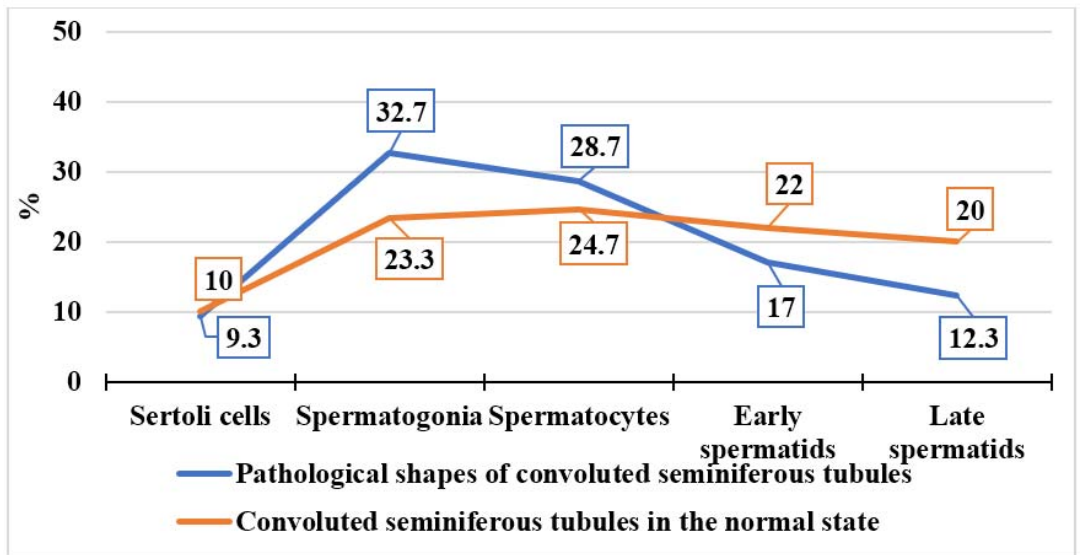

Fig. 4. The ratio of gonadocytes in normal and pathological shapes of seminiferous convoluted tubules during spermatogenesis.

The obtained data may indicate deviations in the process of sperm formation in pathological forms of convoluted seminiferous tubules in comparison with the indicators of normal spermatogenesis. The number of spermatids at the early (14.0\%) and late stages $(12.3 \%)$ of development is relatively small.

\section{Discussion}

Despite the fact that roe deer that have not reached pubescence do not participate in reproduction, histological analysis of the testes and their epididymides showed violations in the composition of their structural elements, which contributes to the further development of abnormalities in the studied organs. Studies by Wagener, Klonisch, Ventrella, and Blottner [10-13] showed that androgen hormones regulate morphological and physiological changes during rutting using Leydig cells, but in our case these cells were in a state of aplasia. In tissue specimen, immature forms of Sertoli cells were found and they are directly dependent on incoming hormones from Leydig cells. Since the main function of Sertoli cells is phagocytic, supporting and trophic, and their number is directly related to the production of spermatogonia [14], the pathological abnormalities shown can presumably have an effect on the disorder of mitotic division of gonadocytes, disrupting further veneral development in an adult animal. These changes contribute to the emergence of underdeveloped primary gonadocytes in convoluted seminiferous tubules. As a result, males who reached pubescence initially had perverted spermatogenesis. Due to violations in Sertoli cells, in addition to defective gonadocytes, the shape of convoluted seminiferous tubules also changed (Fig. 5).

Presumably, as a result of impaired maturation of Sertoli cells performing a supporting function, these changes led to a partial abruption of the coat of the convoluted seminiferous tubule. In its lumen there were found gonadocytes at different stages of development. At the sites of complete abruption of the seminiferous tubule, its breaks were observed. Through the lumen of the convoluted seminiferous tubules, the fluid enriched with spermatozoa at different stages of maturation, along with gonadocytes, moved into the 
epididymis of the testis. According to the study by Schön [15], during the period of rutting, the duct of the testis epididymis with surrounding tissues expands due to the incoming homogeneous mass rich in spermatozoa. However, in our case, elements of the cell epithelium of the duct of the testis epididymis were added to this fluid, due to their abruption and destruction of the duct wall (Fig.6).

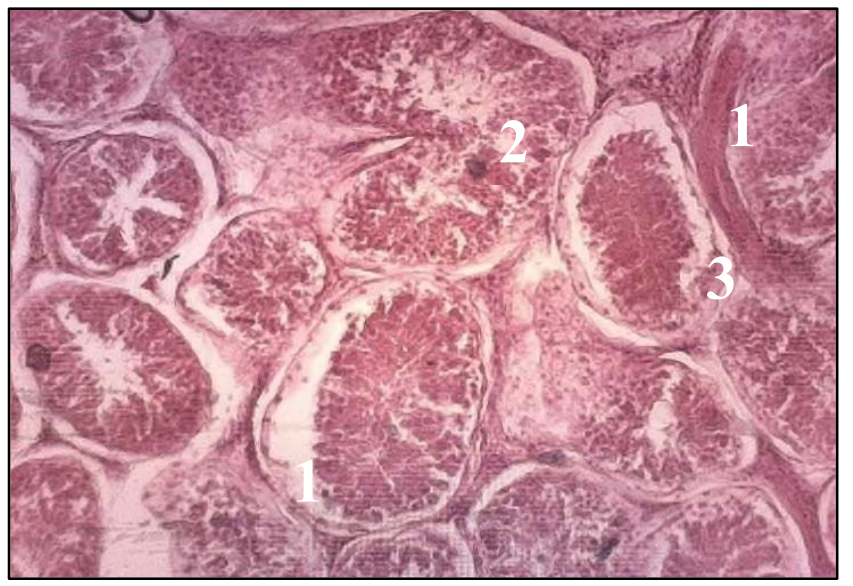

Fig. 5. Convoluted seminiferous tubules of the roe deer(age - 3 years old).Magnification: approx. $\mathrm{x} 18$ vol. $\mathrm{x} 4$. Stained with hematoxylin and eosin: 1 - abruption of the spermatogenic epithelium; 2 violations of the laying of spermatogonia;3-blockage of the lumen of the convoluted seminiferous tubule by gonadocytes.

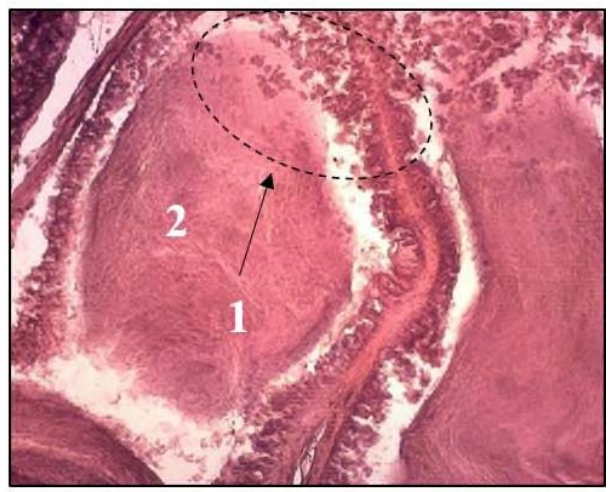

Fig. 6. Duct of the roe's testis epididymis (age - 3 years old).Magnification: approx. $x 18$ vol. $x 4$ Stained with hematoxylin and eosin: 1 - elements of the cell epithelium of the tubule coat; 2 accumulation of spermatozoa.

\section{Conclusions}

1. In all age groups during the rutting period there was observed concomitant pathology of the testes and their epididymides. The largest number of deviations was found in male roe deer aged 2 to 3 years old and older than 5 years old.

2. The main cause of abnormalities in spermatogenesis in roe deer is oligospermia which develops as a result of deep deformations of the convoluted seminiferous tubules and leads to violations of gonadocytes development. 


\section{References}

1. A. V. Senchik, H. Igota, M. A. Bormotov, and S. A. Bochkarev Analysis of the current state of the Siberian roe deer population in the Amur region, Far Eastern Agrarian Bulletin 2 (42), 103-107 (2017) doi:10.24411/1999-6837-2017-00017

2. Jiang, Guangshun \& Minghai, Zhang \& Ma, Jianzhang. Habitat use and separation between red deer Cervus elaphus xanthopygus and roe deer Capreolus pygargus bedfordi in relation to human disturbance in the Wandashan Mountains, Northeastern China. Wildlife Biology 14. 92-100. (2009)

3. A. V. Senchik, N. S. Kukharenko, S. V. Konstantinov, I. E. Sosnovsky, and A. E. Golovchenko "Influence of climatic conditions on the dynamics of the Siberian roe deer (capreolus pyharhus Pall) population in the winter period in the Amur region", Far Eastern Agrarian Bulletin 4 (48), 187-194. (2018) doi:10.24411/1999-6837-201814101

4. A. V. Senchik, I. E. Sos vsky, S. V. Konstanti v, and N. S. Kukharenko The 2019 Flood in the rsk State Nature Reserve and its impact on the populations of Siberian roe deer (capreolus pygargus pallas) and brown bear (ursus arctos), Far Eastern Agricultural Bulletin 1 (53), 62-70 (2020) doi:10.24411/1999-6837-2020-11009

5. F. Ossi, J. Gaillard, M. Hebblewhite. S w sinking depth and forest ca py drive winter resource selection more than su lemental feeding in an alpine population of roe deer, Eur $J$ Wildl Re,s 61, 111-124 (2015). https://doi.org/10.1007/s10344-014-0879-Z

6. A.V. Senchik, Y.S. Guretskaya, M.A. Bormotov International Journal of Civil Engineering and Tech logy (IJCET) - Scopus Indexed 9 (2018)

7. K. Kozioł, M. Koziorowski Morphological defects of epididymal spermatozoa in male roe deer (Capreolus capreolus) during the reproductive season, Pol J Vet Sci. 18(3), 565-572 (2015) doi:10.1515/pjvs-2015-0073

8. F. Martinez-Pastor, C. Guerra, M. Kaabi Season effect on genitalia and epididymal sperm from Iberian red deer, roe deer and Cantabrian chamois, Therioge logy.63(7), 1857-1875 (2005) doi:10.1016/j.therioge logy.2004.08.006

9. A. Imi, A. Zan ni, N. Govoni Uncovering the Physiological Mechanisms Underlying the Roe Deer (Capreolus capreolus) Testicular Cycle: Analyses of Gelatinases and VEGF Patterns and Correlation with Testes Weight and Testosterone. Animals (Basel). 10(3), 444 (2020) doi:10.3390/ani10030444

10. A. Wagener, S. Blottner, F. Göritz, W. J. Streich, J. Fickel Circannual changes in the expression of vascular endothelial growth factor in the testis of roe deer (Capreolus capreolus). Anim Reprod Sci.117(3-4),275-278 doi:10.1016/j.anireprosci.2009.05.006

(2010)

11. T. Klonisch, J. Schön, S. Hombach-Klonisch, S. Blottner. The roe deer as a model for studying seasonal regulation of testis function., J Androl. 29(1), 122-128 (2006) doi:10.1111/j.1365-2605.2005.00603.x

12. D. Ventrella, A. Elmi, F. Barone, G. Carnevali, N. Govoni, ML. Bacci. Hair Testosterone and Cortisol Concentrations in Pre- and Post-Rut Roe Deer Bucks: Correlations with Blood Levels and Testicular Morphometric Parameters, Animals (Basel) 8(7), 113. (2018) doi:10.3390/ani8070113

13. S. Blottner, J. Schoen Minimal activity in both proliferation and apoptosis of interstitial cells indicates seasonally persisting Leydig cell population in roe deer. Cell Tissue Res. 321(3), 473-478 (2005) doi:10.1007/s00441-005-1132-6 
14. E. Pintus, JL. Ros-Santaella, JJ. Garde. Beyond Testis Size: Links between Spermatogenesis and Sperm Traits in a Seasonal Breeding Mammal, 10(10), e0139240. (2015) doi:10.1371/journal.pone.0139240

15. J. Schön, S. Blottner. Seasonal variations in the epididymis of the roe deer (Capreolus capreolus). Anim 111(2-4), 344-352 (2009) doi:10.1016/j.anireprosci.2008.03.008 